\title{
Quin temps, aquest hivern!
}

Josep Enric Llebot. Departament de Física, Universitat Autònoma de Barcelona. enric.llebot@uab.cat Joan Aliberas. IES Josep Puig i Cadafalch, Mataró. jalibera@xtec.cat

Aquest hivern no ha estat com els altres: hem tingut pluja durant molts dies. Això vol dir que s'ha aturat el canvi climàtic? Que hem deixat enrere els hiverns amb poca pluja? Suposa la solució del problema de la sequera?

Paraules clau: clima, oscilllació nord-atlàntica, NAO, cel·la de Hadley

Un tema recurrent aquest hivern ha estat el del mal temps. S'ha comentat com ha estat de freqüent la pluja i fins i tot, quan feia prou fred, la nevada en llocs poc freqüents.

\section{Algunes dades}

Les dades de molts observatoris (vegeu per exemple les de Reus a les figs. 1 i 2) confirmarien que el total de precipitació i el nombre de dies amb precipitació han estat superiors als habituals.
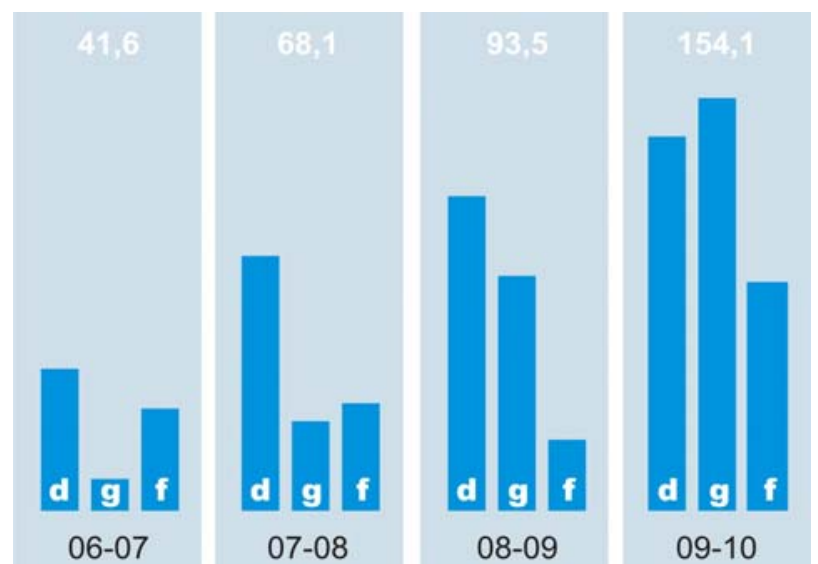

Figura 1. Precipitació total a Reus en els mesos de desembre, gener i febrer dels darrers anys. Els números superiors indiquen la precipitació acumulada en aquests tres mesos cada temporada. (Dades: www.meteoreus.net).

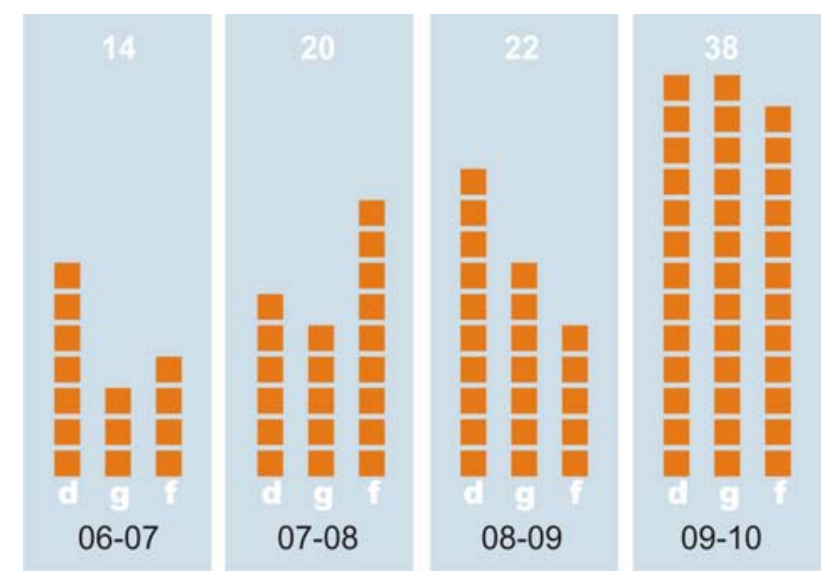

Figura 2. Dies de pluja superior a 0,2 $\mathrm{mm}$ a Reus durant els mesos de desembre, gener i febrer. El nombre total per temporada s'indica a dalt.

(Dades: www.meteoreus.net).

És un canvi de tendència climàtica? L'escalfament global s'ha aturat o fa marxa enrere? Hem de deixar de patir per l'aigua?

No ens precipitem. Les tendències climàtiques cal mesurar-les amb sèries de temps molt més llargues i amb dades més completes. Ara com ara, tot fa pensar que som davant d'un episodi normal dins de la variabilitat que caracteritza el temps del nostre país.

De totes formes, aquest hivern s'han donat algunes circumstàncies que poden ajudar a explicar el temps que hem tingut. 


\section{L'oscil-lació nord-atlàntica}

La circulació general de l'atmosfera (fig. 3) genera un cinturó de zones d'alta pressió a cada hemisferi terrestre. Allí l'aire sec, més pesat que no pas l'humit, descendeix i s'escalfa, donant lloc a un cinturó de deserts i terres àrides a cada hemisferi. Per exemple, recordem on són els deserts del Sàhara, del Kalahari o d'Austràlia. Són zones d'altes pressions. (Amb l'escalfament global, és previsible que les cel.les de Hadley, molt energètiques, adquireixen encara més energia i això les faria créixer en direcció al pol. És per això que el clima àrid podria amenaçar el sud de la península ibèrica).

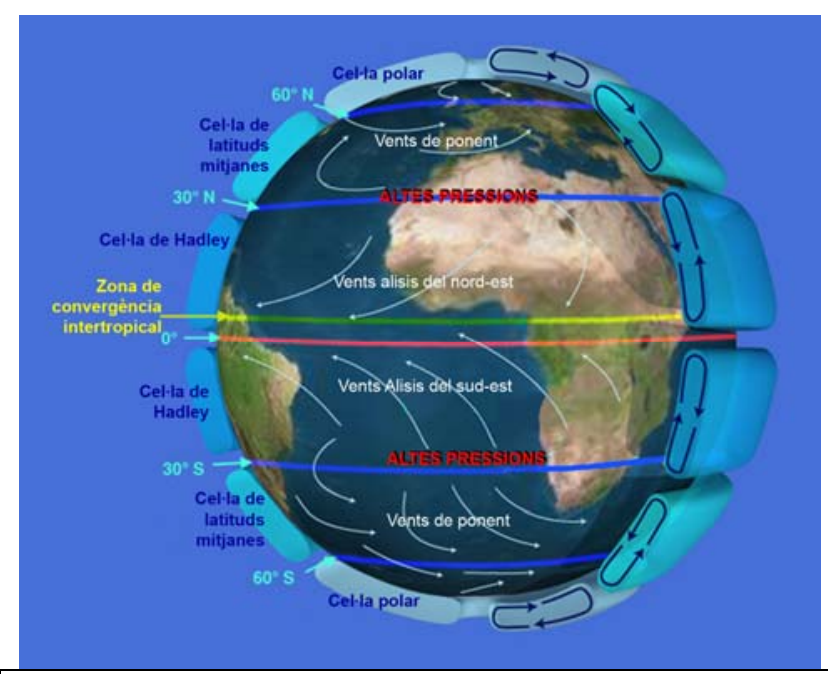

Figura 3. Circulació general atmosfèrica mostrant les diverses cel-les i les altes pressions corresponents a uns $30^{\circ}$ de latitud i les baixes a $60^{\circ}$, tant al nord com al sud.

(Font: http://sealevel.jpl.nasa.gov)

Durant l'hivern, la cel.la de Hadley té menys energia i la zona d'altes pressions on acaba la de l'hemisferi nord és generalment més al sud, permetent que les depressions que circulen per la zona de vents de ponent arribin a Galícia portant-hi pluja i fred.

Però de vegades no és així, com a l'hivern del 2007, quan l'anticicló de les Açores, aleshores molt consolidat, impedia el pas de borrasques cap a la península i sobretot cap al Mediterrani, provocant greus problemes de sequera a Catalunya. Les borrasques, en canvi, portaven la precipitació cap a les illes Britàniques i nord d'Europa.

Cap als $60^{\circ}$ de latitud hi ha un altre cinturó a cada hemisferi on l'aire ascendeix i s'inestabilitza. Aquests cinturons són zones de baixes pressions $\mathrm{i}$ cadascun correspon aproximadament al front polar que separa les masses d'aire de les dues cel.les: la polar i la de les latituds mitjanes, unes masses de característiques força diferents, sobretot en temperatura.

Com que el front polar és inestable s'ondula produint remolins amb masses d'aire fred i càlid sense barrejar: són les borrasques, sistemes de baixa pressió que porten associades no només un gradient de pressió i per tant vent més o menys fort que gira en sentit antihorari a l'hemisferi nord, sinó inestabilitat atmosfèrica deguda a la interacció entre les diverses masses d'aire (fredes i càlides).

És per això que a la part de l'Atlàntic que pertany a l'hemisferi nord es presenta habitualment una gran zona d'altes pressions centrada a les illes Açores (el conegut anticicló de les Açores) mentre que cap a la zona d'Islàndia hi ha baixes pressions que van dirigint les borrasques cap a Europa, empeses pels vent de ponent, dominants en la nostra cel.la atmosfèrica de latituds mitjanes.

Aquesta és una situació habitual, amb alta pressió al sud de l'Atlàntic nord i baixes pressions més al nord. Meteorològicament parlant significa temps humit i plujós al nord d'Europa (fig. 4) i temps eixut i càlid al sud on som nosaltres. Les depressions no poden arribar a les nostres latituds, rebutjades per la gran barrera que representa l'anticicló.

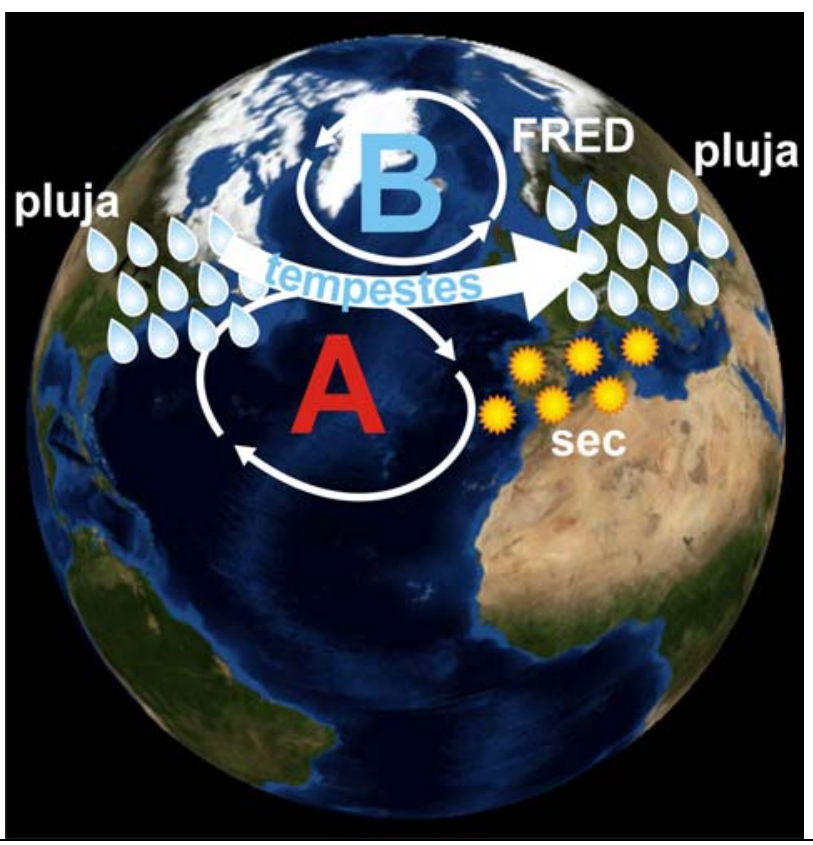

Figura 4. Fase positiva de l'Oscil-lació de l'Atlàntic Nord.

Però de tant en tant aquestes altes pressions del sud i les baixes del nord es debiliten. Els patrons de temps a l'Atlàntic nord solen oscil.lar entre aquestes dues possibilitats. S'anomena Oscil.lació de l'Atlàntic Nord (NAO, per les seves sigles en an- 
glès). La situació representada a la fig. 4 s'anomena fase positiva de la NAO.

Durant la fase negativa (fig. 5) el debilitament de l'anticicló de les Açores ja no li permet impedir el pas de les borrasques, de forma que aquestes poden penetrar molt més al sud del que ho fan durant la fase positiva.

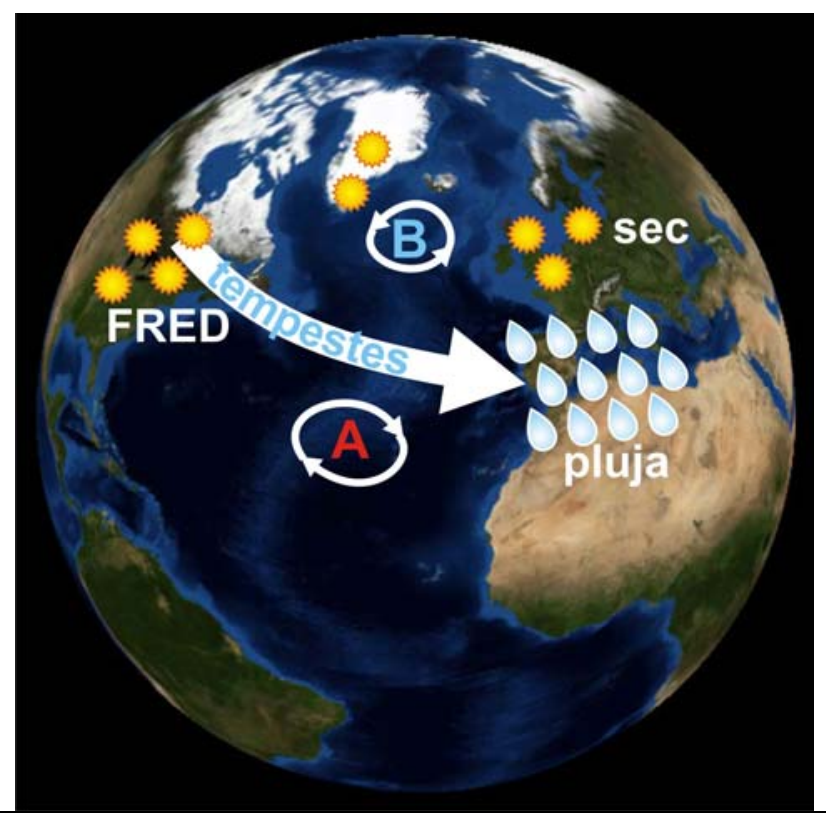

Figura 5. Fase negativa de l'Oscil-lació de l'Atlàntic Nord.

Això ens proporciona un temps humit i més fred, mentre que al nord d'Europa el temps es fa més eixut. És el que ha estat passant durant aquest hivern.

\section{L'índex NAO}

Per fer el seguiment d'aquesta oscil-lació nordatlàntica s'ha creat un índex NAO que s'elabora a partir de la diferència de pressions entre les Açores (o Lisboa) i Islàndia. Quan aquesta diferència queda per damunt d'un cert valor, es considera que s'està en la fase positiva, mentre que si la diferència en queda per sota, és la fase negativa.

Com es pot veure a la gràfica de la fig. 6 , les alternances entre una fase i l'altra són freqüents però sense cap periodicitat clara.

Un altre factor a tenir en compte en el temps d'aquest hivern és l'aparició d'un potent anticicló a Sibèria i Rússia europea. Com que el terra es refreda mot ràpid, l'aire que hi entra en contacte també es refreda molt. La seva densitat augmenta i la seva tendència a moure's va minvant. La poca mobilitat de l'aire caracteritza aquesta mena d'antici- clons, anomenats radiatius. (A una altra escala és el que passa en les fondalades de certes comarques durant l'hivern, que es refreden força més que la resta del territori).

Aquest anticicló al nord d'Euràsia bloqueja el pas de les borrasques atlàntiques, que no només es veuen obligades a baixar de latitud i passar pel nostre país, sinó que també de vegades no acaben de trobar una ruta per continuar el seu camí i sembla que s'entretinguin entre nosaltres, oferint-nos dies de pluja persistent.

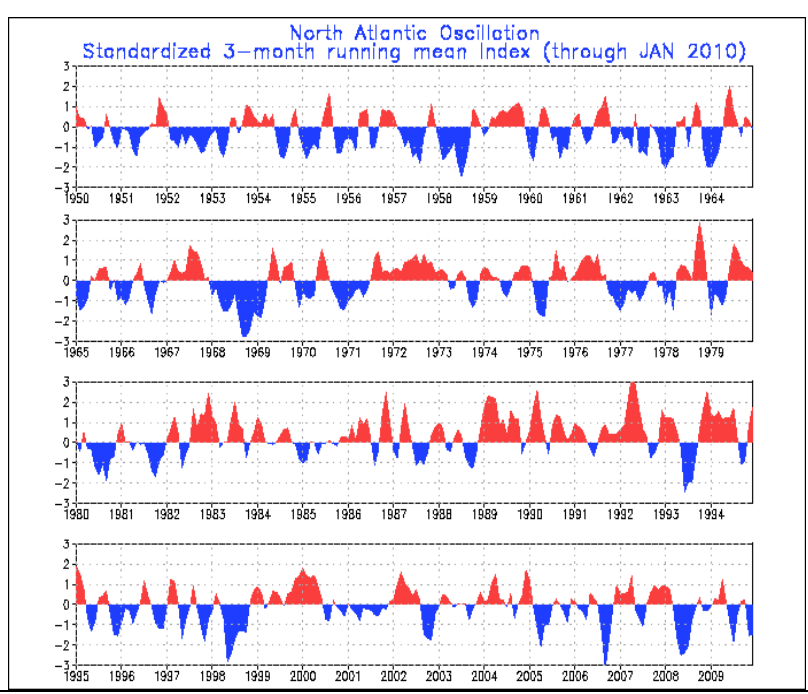

Figura 6. Evolució del valor de l'índex NAO entre $1950 \mathrm{i}$ el gener del 2010. (www.cpc.ncep.noaa.gov)

\section{I el Sol?}

En aquests moments el Sol està sortint amb lentitud d'una fase de mínima activitat. Podria ser que aquesta baixa activitat solar hagués contribuït significativament al refredament de l'atmosfera?

La resposta és que no. Vegem perquè.

Els cicles solars tenen un període d'onze anys però signifiquen variacions en la radiació solar a la Terra de només uns $2 \mathrm{~W} / \mathrm{m}^{2}$. (Aquest és un dels motius perquè les mitjanes meteorològiques es solen fer sobre un període de 30 anys, absorbint d'aquesta manera l'efecte dels cicles solars). Es tracta, doncs, d'un valor molt petit si el comparem amb el de la constant solar, que té un valor mitjà de $1368 \mathrm{~W} / \mathrm{m}^{2}$. Suposa amb prou feines una variació del $0,15 \%$. La baixa activitat del Sol no pesa prou per explicar per si sola el que ha passat aquest hivern.

Una altra cosa seria que aquesta disminució durés molt de temps. Per exemple, se sap que les glaciacions es van produir amb descensos de la radiació solar de només $1 \mathrm{~W} / \mathrm{m}^{2}$, uns descensos, però, que es van mantenir durant mil.lennis. La 
fluctuació de l'activitat solar en la qual estem immersos té un cicle curt pel que fa al comportament climàtic i és inapreciable a llarg termini. Ara som a punt de tornar a emprendre la fase ascendent de la seva activitat.

\section{La sequera}

Finalment, un breu comentari sobre el tema de la sequera.

Com es dedueix de tot el que hem anat veient fins aquí, els episodis de pluja d'aquest hivern responen a variacions aleatòries. Aquest hivern hem tingut una fase negativa de la NAO, que ha afavorit les pluges a Catalunya; però no hem d'oblidar que la fase positiva, que tard o d'hora tornarà, significa per a nosaltres una minva en la precipitació.

Per altra banda, tinguem en compte que l'important augment recent de la població suposa un in- crement de la càrrega sobre els nostres sistemes hídrics. Si a més a més hi afegim l'efecte del canvi climàtic, que sembla que ha de fer disminuir la precipitació a casa nostra, sumat a l'abandonament dels conreus i el creixement dels boscos, que retenen i transpiren més quantitat d'aigua, veurem que tot plegat contribueix a fer minvar el cabal dels nostres rius.

Malauradament, doncs, no podem donar per superat ara per ara en el nostre entorn el problema de l'escassesa d'aigua provinent de les precipitacions.

\section{Bibliografia}

LLEBOT, J.E. (2005) El temps és boig? Barcelona: Rubes ed. 